\title{
Genetic diversity and relationship of Korean chicken breeds using 12 microsatellite markers
}

\author{
Yesong Kim ${ }^{1}$, Ji Hye Yun ${ }^{1}$, Seon Jeong Moon ${ }^{2}$, Jiyeon Seong, ${ }^{3}$ and Hong Sik Kong ${ }^{1,3,4, *}$ \\ ${ }^{1}$ Department of Applied Biotechnology, The Graduate School of Hankyong National University, Anseong 17579, Korea \\ ${ }^{2}$ Korea Institute for Animal Products Quality Evaluation, Sejong 30100, Korea \\ ${ }^{3}$ Genomic Informatics Center, Hankyong National University, Anseong 17579, Korea \\ ${ }^{4}$ Gyeonggi Regional Research Center, Hankyong National University, Anseong 17579, Korea
}

Received August 25, 2021

Revised September 18, 2021

Accepted September 22, 2021

*Correspondence

Hong Sik Kong

E-mail: Kebinkhs@hknu.ac.kr

ORCID

https://orcid.org/0000-0003-1144-016X

This thesis is based on Yesong Kim's Master Thesis (Korean native commercial chicken identification and genetic diversity analysis using Microsatellite Marker; 2020.12).

\begin{abstract}
A number of Korean Chicken breeds were registered in Domestic Animal Diversity Information System (DAD-IS, http://dad.fao.org/) of the Food and Agriculture Organization (FAO). Evaluation of genetic diversity and relationship of local breeds is an important factor towards the identification of unique and valuable genetic resources. Therefore, this study aimed to analysis the genetic diversity and relationship of 22 Korean Chicken breeds using 12 microsatellite (MS) markers. The mean number of alleles for each variety was 5.52, ranging from a 3.75 (Leghorn F; NF) to a 7.0 (Ross). The most diverse breed was the Hanhyup3 (HCC), which had the highest expected heterozygosity $\left(\mathrm{H}_{\mathrm{Exp}}\right)(0.754)$ and polymorphic information content (PIC) (0.711). The NF was the least diverse population, having the lowest $\mathrm{H}_{\mathrm{Exp}}(0.467)$ and PIC (0.413). As a result of the principal coordinates analysis (PCoA) and factorial correspondence analysis (FCA) confirmed that Hy-line Brown (HL) and Lohmann Brown (LO) are very close to each other and that Leghorn and Rhode Island Red (RIR) are clearly distinguished from other groups. Thus, the reliability and power of identification using 12 types of MS markers were improved, and the genetic diversity and probability of individual discrimination were confirmed through statistical analysis. This study is expected to be used as basic data for the identification of Korean chicken breeds, and our results indicated that these multiplex PCR marker sets will have considerable applications in population genetic structure analysis.
\end{abstract}

Keywords: genetic diversity, Korean native chicken, microsatellite marker, relationship

\section{INTRODUCTION}

Chicken is one of the major livestock, especially for supplying proteins to human and the Korean native chicken (KNC) has been documented since approximately 2,000 years ago (Seo et al., 2013; Seo et al., 2015). But, due to their poor commercial performance, Korean native chicken breeds almost became extinct and the breeds that existed before the Korean War (1950-1953), are almost all extinct (Seo et al., 2013; Choi et al., 2015). After the Korean War, commercial native chicken companies maintained various independent breeds while continuing production and market distribution (Seo et al., 2018). Since 1992, a KNC conservation project was launched by the National Institute of Animal Science (NIAS) in an attempt to restore local chicken breeds (Choi et al., 2015; Roh et al., 2019). So, KNC breeds and other imported and adapted breeds in the 1960s have been restored (Heo et 
al., 2011; Choi et al., 2015).

NIAS has preserved two types of purebred chicken breeds: purebred KNCs, which include five breeds with different feather colors \{red-brown (NR), yellow-brown (NY), gray-brown (NG), black (NL) and white (NW)\} and the "imported and adapted chickens", which includes two Rhode Island Red breeds, two Cornish breeds and two Leghorn breeds (Seo et al., 2018; Choi et al., 2019). Also, NIAS developed the Woorimatdag version 1 (WM1) and 2 (WMT). WM1 breeds were commercial, KNC breeds generated form crossbreeding fast growing native male and good tasting female with increased egg production, and WM2 breeds were modified version of WM1 breeds with increased growth rates (Park et al., 2010; Choi et al., 2015). The private native chicken breeding-stock company (Hanhyup) is responsible for more than $80 \%$ of the native chicken distribution in Korea and has maintained purebred chicken breeds (Hanhyup breeds) for commercial use for the past 60 years (Seo et al., 2018; Choi et al., 2019). Hanhyup breeds produced by mating the KNC and economically superior and naturalized breeds (Seo et al., 2017). A number of Korean chicken breeds were registered in Domestic Animal Diversity Information System (DAD-IS, http://dad.fao.org/) of the Food and Agriculture Organization (FAO). But, at present, sufficient detailed information about these Korean chicken breeds is not available. Evaluating the genetic diversity and genetic structure of these breeds is very important step towards identifying and conserving valuable genetic resources (Suh et al., 2014).

Genetic marker polymorphisms provide a reliable method to assess the biodiversity within and among chicken breeds. Microsatellite markers or simple-sequence repeat (SSR) markers, are highly polymorphic, one to six base pair repeats, widely used since they are numerous, randomly distributed in the genome, and show co-dominant inheritance (Cheng et al., 1994; Crooijmans et al., 1996; Choi et al., 2015). Thus, microsatellites have been identified as reliable markers in chickens (Hillel et al., 2003; Tadano et al., 2007; Suh et al., 2014). The identification of these specific markers could aid the selection process for the development of native chickens that are more suitable for the chicken industry in Korea. Therefore, the aim of this study was to characterize the genetic diversity Korean chicken breeds available in Korea based on 12 microsatellite markers.

\section{MATERIALS AND METHODS}

\section{Animal and DNA isolation}

A total of 782 individual samples from 22 Korean chicken breeds: 5 breeds of broilers \{Arbor Acres (AB), Black Cornish (NH), Brown Cornish (NS), Cobb, Ross\}, 4 breeds of laying hens $\{\mathrm{Hy}$-line Brown (HL), Lohmann (LO), Leghorn F (NF), Leghorn K (NK)\} and 13 breeds of Dualpurpose \{Ogye (NO), Hanhyup A (HA), Hanhyup 3 (HCC), Hanhyup Z (HZ), WM, WMT, Rhode Island Red C (NC), Rhode Island Red D (ND), NR, NY, NW, NG, NL\} were collected from NIAS and Hanhyup. Genomic DNA was extracted from blood samples collected from the wing veins into ethylene diamine tetra acetic acid (EDTA) - coated tunes. Genomic DNA extraction from blood samples the using the methods described for AccuPrep ${ }^{\circledR}$ Blood DNA Extraction Kit (Bioneer, Korea). The concentration of DNA samples was measured using NanoDrop ND-1000 spectrophotometer (Thermo Scientific, USA) and stored at $-20^{\circ} \mathrm{C}$.

\section{Microsatellite (MS) marker and polymerase chain reaction (PCR) amplification}

Previously, 27 Microsatellite markers were investigated for the discrimination of KNC and commercial KNC (Seo et al., 2015; Seo et al., 2017; Choi et al., 2019). From these results, a total of 12 MS markers were initially selected, which have high expected heterozygosity $\left(\mathrm{H}_{\text {Exp }}\right)$ and polymorphic information content (PIC) values (Supplementary Table 1).

All 782 DNA samples were amplified using a $\mathrm{T} 100^{\mathrm{TM}}$ Thermal Cycler (Bio-Rad, USA). The amplifications were carried out using $15 \mu \mathrm{L}$ reaction mixtures containing genomic DNA (5-20 ng), 10 pmol primer mix, $2.5 \mathrm{mM}$ of each dNTPs (GeNet Bio, Korea) and 1.5 U Hot Start Taq polymerase (GeNet Bio, Korea) which were then subjected to 30 cycles of $30 \mathrm{~s}$ at $95^{\circ} \mathrm{C}, 30 \mathrm{~s}$ at $58^{\circ} \mathrm{C}$, and $1 \mathrm{~min}$ at $72^{\circ} \mathrm{C}$.

\section{Genotyping and statistical analysis}

The amplified DNA was performed using an automated Genetic Analyzer 3730 (Applied Biosystems, USA). The genotyping reaction contained $1 \mu \mathrm{L}$ of PCR products, $8.9 \mu \mathrm{L}$ of Hi-Di formamide, and $0.1 \mu \mathrm{L}$ of GeneScan500LIZ size standard in $10 \mu \mathrm{L}$ total volume. The results were obtained using GeneMapper V 5.0 (Applied Biosystems, USA). 
J Anim Reprod Biotechnol Vol. 36, No. 3, September 2021

Table 1. Statistical analysis result of 12 ms markers

\begin{tabular}{|c|c|c|c|c|c|c|c|}
\hline Marker & NA & $\mathrm{H}_{\operatorname{Exp}}$ & $\mathrm{H}_{O b s}$ & PIC & $\mathrm{F}_{s t}(\theta)$ & $\mathrm{F}_{i t}(F)$ & $\mathrm{F}_{i s}(f)$ \\
\hline ADL0293 & 11 & 0.5704 & 0.5841 & 0.5205 & 0.224 & 0.172 & -0.066 \\
\hline ADL0304 & 10 & 0.6365 & 0.5805 & 0.5755 & 0.137 & 0.175 & 0.044 \\
\hline GСT0016 & 15 & 0.6508 & 0.3424 & 0.5781 & 0.232 & 0.57 & 0.441 \\
\hline LEI0094 & 17 & 0.7063 & 0.6871 & 0.6548 & 0.136 & 0.104 & -0.037 \\
\hline MCW0029 & 18 & 0.7034 & 0.7202 & 0.6536 & 0.187 & 0.149 & -0.046 \\
\hline MCW0104 & 22 & 0.6938 & 0.651 & 0.6446 & 0.222 & 0.268 & 0.06 \\
\hline MCW0123 & 7 & 0.5123 & 0.5323 & 0.4452 & 0.25 & 0.202 & -0.065 \\
\hline MCW0127 & 19 & 0.7416 & 0.6631 & 0.6905 & 0.096 & 0.148 & 0.057 \\
\hline MCW0145 & 9 & 0.7184 & 0.7451 & 0.6595 & 0.118 & 0.064 & -0.062 \\
\hline MCW0330 & 11 & 0.6607 & 0.5654 & 0.599 & 0.216 & 0.277 & 0.078 \\
\hline
\end{tabular}

NA, Number of Alleles; $\mathrm{H}_{\text {Exp }}$, Expected heterozygosity; $\mathrm{H}_{\mathrm{Obs}}$, Observed heterozygosity; PIC, Polymorphism Information Content; $\mathrm{F}_{\text {st }}$, Genetic distance; $\mathrm{F}_{\text {it }}$ Total inbreeding; $F_{i s}$, Within inbreeding.

Table 2. MNA, $\mathrm{H}_{E x p}, \mathrm{H}_{O b s}$ and PIC observed across 12 MS markers in 22 Korean chicken breeds

\begin{tabular}{|c|c|c|c|c|}
\hline Pop & MNA & $\mathrm{H}_{\text {Exp }}$ & $\mathrm{H}_{\text {obs }}$ & PIC \\
\hline COBB & 6.33 & 0.7266 & 0.6008 & 0.6716 \\
\hline $\mathrm{HCC}$ & 6.25 & 0.7541 & 0.7109 & 0.7113 \\
\hline $\mathrm{HL}$ & 4.83 & 0.6804 & 0.8389 & 0.6179 \\
\hline $\mathrm{HZ}$ & 6.25 & 0.7253 & 0.6708 & 0.6786 \\
\hline $\mathrm{NC}$ & 4.17 & 0.5996 & 0.4138 & 0.5306 \\
\hline ND & 4.67 & 0.6446 & 0.5241 & 0.5775 \\
\hline NF & 3.75 & 0.4679 & 0.3924 & 0.4131 \\
\hline NG & 5.83 & 0.6703 & 0.5956 & 0.6182 \\
\hline $\mathrm{NH}$ & 4.67 & 0.5860 & 0.4083 & 0.5265 \\
\hline NR & 6.50 & 0.7162 & 0.6054 & 0.6571 \\
\hline NS & 5.00 & 0.6237 & 0.4697 & 0.5624 \\
\hline NW & 6.08 & 0.6914 & 0.6480 & 0.6353 \\
\hline NY & 6.75 & 0.7260 & 0.6414 & 0.6713 \\
\hline ROSS & 7.00 & 0.7100 & 0.6833 & 0.6659 \\
\hline WM & 6.42 & 0.7256 & 0.7092 & 0.6826 \\
\hline WMT & 6.58 & 0.7097 & 0.6260 & 0.6619 \\
\hline Mean & 5.52 & 0.666 & 0.606 & 0.61 \\
\hline
\end{tabular}

MNA, Mean Number of Alleles; $\mathrm{H}_{\text {Exo }}$, Expected heterozygosity; $\mathrm{H}_{\text {obs }}$, Observed heterozygosity; PIC, Polymorphism Information Content; Arbor Acres (AB), Cobb (COBB), Hanhyup A (HA), Hanhyup 3 (HCC), Hy-line Brown (HL), Hanhyup Z (HZ), Lohmann brown (LO), Rhode Island Red C (NC), Rhode Island Red D (ND), Leghorn F (NF), Gray Korea Native Chicken (NG), Black Cornish (NH), Leghorn K (NK), Black Korea Native Chicken (NL), Ogye (NO), Red Korea Native Chicken (NR), Brown Cornish (NS), White Korea Native Chicken (NW), Yellow Korea Native Chicken (NY), Ross (ROSS), Woorimatdag1 (WM), Woorimatdag2 (WMT). 
The genotyped data were analyzed using MS toolkit software (Park, 2001) version 3.1 to calculate allele frequencies at each locus for each population, $\mathrm{H}_{\text {Exp }}$, observed heterozygosity $\left(\mathrm{H}_{O b s}\right)$, and PIC values. The amount of inbreeding-like effects within subpopulations (genetic distance; $\mathrm{F}_{\mathrm{st}}$ ), among subpopulations (within inbreeding, $\mathrm{F}_{i s}$ ), and within the entire population (total inbreeding, $\mathrm{F}_{i t}$ ) were analyzed by $F$-statistics (Wright, 1965). Wright's Fstatistics were computed according to Weir and Cockerham using FSTAT software (Weir and Cockerham, 1984). The Neighbor - Joining method was used to construct a phylogenetic tree (Saitou and Nei, 1987). The principal coordinates analysis (PCoA) was conducted for 22 chicken breeds using GenAlEx 6.4 program. The Factorial correspondence analysis (FCA), which is a weighted principal component analysis, was performed using the allele frequency data for the individuals of all 22 breeds and the 12 MS markers using GENETIX software (Belkhir, 2003; Tantia et al., 2006).

\section{RESULTS}

\section{Polymorphisms of microsatellite markers}

The number of alleles, $\mathrm{H}_{E x p}, \mathrm{H}_{O b s}$, and PIC values for the 12 markers used in this study summarized in Table 1 . A total of 164 different alleles were detected, ranging from 7 (MCW0123) to 22 (MCW0104) and the mean number of alleles (MNA) was 13.667. $\mathrm{H}_{\text {Exp }}$ and $\mathrm{H}_{O b s}$ ranged from 0.512 (MCW0123) to 0.742 (MCW0127) and 0.342 (GCT0016) to 0.745 (MCW0145), with mean value of 0.666 and 0.606 , respectively. PIC values ranged from 0.445 (MCW0123) to 0.691 (MCW0127), with a mean value of 0.610. Estimation of genotypic diversity in heterozygosity and PIC value of MS markers were previously used for determining animal breed selection (Berthouly et al., 2008; Choi et al., 2019). For the animal traceability, PIC $>0.5$ and $\mathrm{H}_{E x p}>0.6$ are the most reasonable informative locus for application in genetics (Botstein et al., 1980; Jung et al., 2021).

$\mathrm{F}$-statistic were estimated in a fixation index as genetic differentiation $\left(\mathrm{F}_{\mathrm{st}}\right)$, the global heterozygote deficit among 22 chicken breeds $\left(\mathrm{F}_{\mathrm{it}}\right)$, and the heterozygote deficit within the breed $\left(\mathrm{F}_{i s}\right)$ among the 12 MS markers (Table 1). Among these markers, $\mathrm{F}_{\text {st }}$ values ranged from 0.096 (MCW0127) to 0.232 (GCT0016); $F_{i t}$ values ranged from 0.064 (MCW0145) to 0.364 (ADL0317) and the $F_{\text {is }}$ ranged from -0.065 (MCW0123) to 0.218 (ADL0317). The estimated mean value of the $F_{s t}, F_{i t}$, and $F_{i s}$ were $0.183,0.231$ and 0.058 , respectively (Table 1).

The breed statistics generated by the 12 microsatellite markers in 22 chicken breeds are shown in Table 2. The mean NA for each variety was 5.52, ranging from a 3.75 (NF) to a 7.0 (ROSS). The most diverse breed was the HCC, which had the highest $\mathrm{H}_{\text {Exp }}(0.754)$ and PIC (0.711). The $\mathrm{NF}$ was the least diverse population, having the lowest $\mathrm{H}_{\text {Exp }}(0.467)$ and PIC (0.413).

\section{Genetic distance among Korean Chicken breeds}

Fig. 1 illustrates the population relationships based on the PCoA using individual multilocus genotypes of $12 \mathrm{MS}$ markers. The first and second components contributed $31.48 \%$ and $25.29 \%$, respectively, and the third component contributed $15.8 \%$. Clearly, by the first component, Leghorn (NF, NK) was confirmed to be separated from the other groups. Cornish (NS, NH) was confirmed near the KNC, HL and LO by the second component. And it showed that $\mathrm{HL}$ and LO are genetically very close by the variance of first and second components.

Also, we conducted FCA, using allele frequencies of the 12 MS markers, as an alternative approach to understand the genetic relationships among breeds (Fig. 2). Fig. 2 shows close relationship among individuals which belong to the KNC, Cornish, and NO, and it was the leghorn (NK,

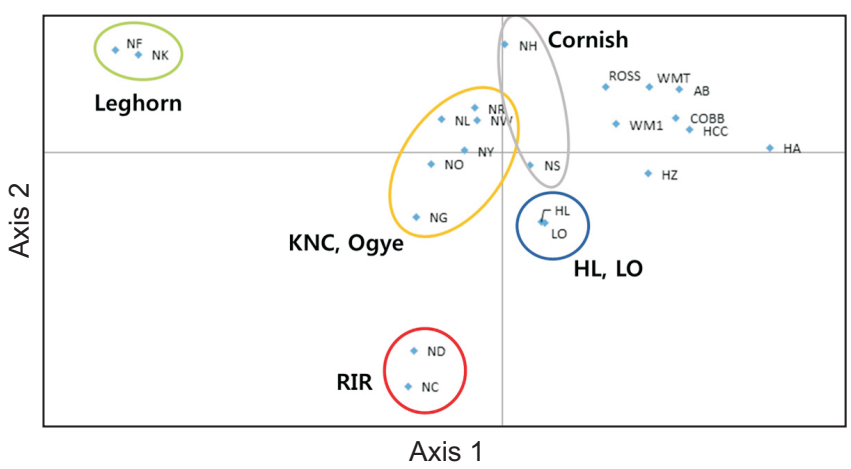

Fig. 1. PCoA of allele frequencies from 12 MS marker typed in 22 population using the GenAIEx, The population acronyms are as follows ; Arbor Acres (AB), Cobb (COBB), Hanhyup A (HA), Hanhyup 3 (HCC), Hy-line Brown ( $\mathrm{HL})$, Hanhyup Z (HZ), Lohmann brown (LO), Rhode Island Red (RIR) [ Rhode Island Red C (NC), Rhode Island Red D (ND)], Leghorn F (NF), Gray Korea Native Chicken (NG), Black Cornish $(\mathrm{NH})$, Leghorn K (NK), Black Korea Native Chicken (NL), Ogye (NO), Red Korea Native Chicken (NR), Brown Cornish (NS), White Korea Native Chicken (NW), Yellow Korea Native Chicken (NY), Ross (ROSS), Woorimatdag1 (WM), Woorimatdag2 (WMT). 


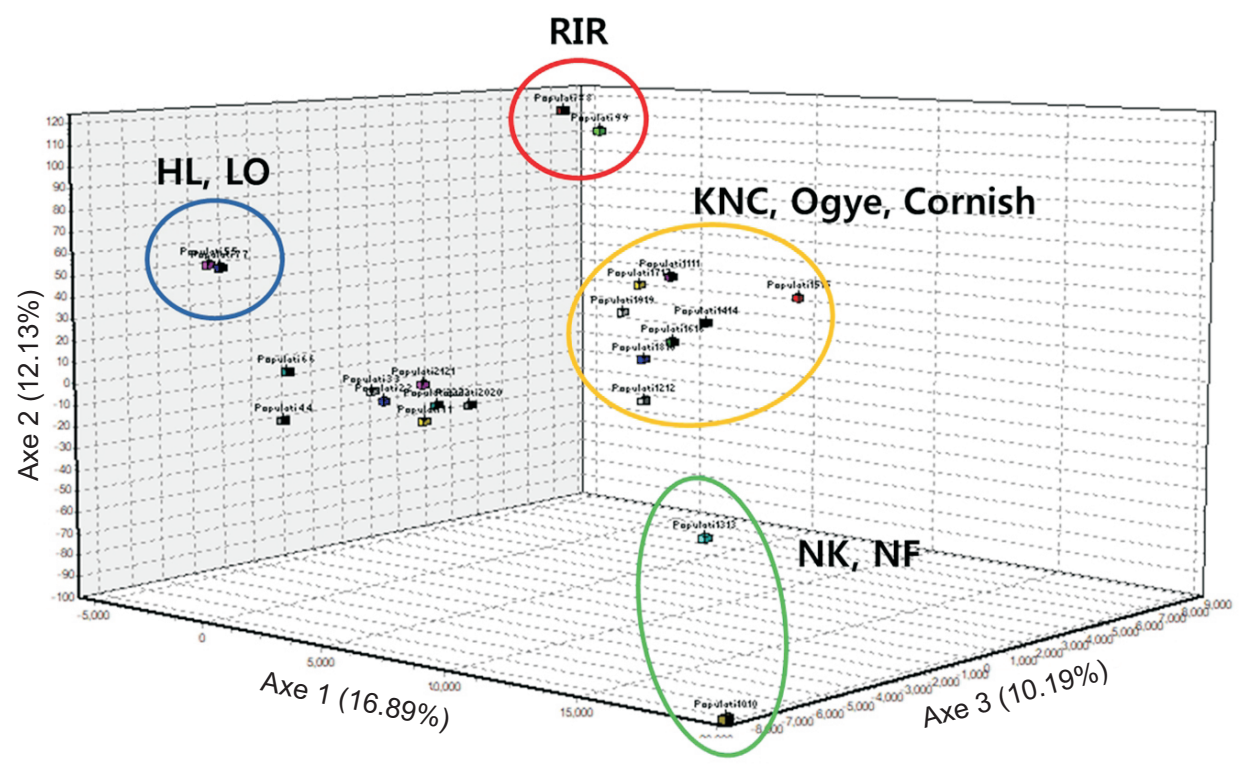

Fig. 2. Factorial correspondence analysis (FCA) for 12 microsatellite loci genotype in 22 population using GENETIX ver. 4.05. Population, Population1: Arbor Acres, Population2: Cobb, Population3: Hanhyup A, Population4: Hanhyup 3, Population5: Hy-line Brown, Population6: Hanhyup Z, Population7: Lohmann Brown, Population8: Rhode Island Red C, Population9: Rhode Island Red D, Population10: Leghorn F, Population11: Gray Korea Native Chicken, Population12: Black Cornish, Population13: Leghorn K, Population14: Black Korea Native Chicken, Population15: Ogye, Population16: Red Korea Native Chicken, Population17: Brown Cornish, Population18: White Korea Native Chicken, Population19: Yellow Korea Native Chicken, Population20: Ross, Population21: Woorimatdag 1, Population22: Woorimatdag 2.

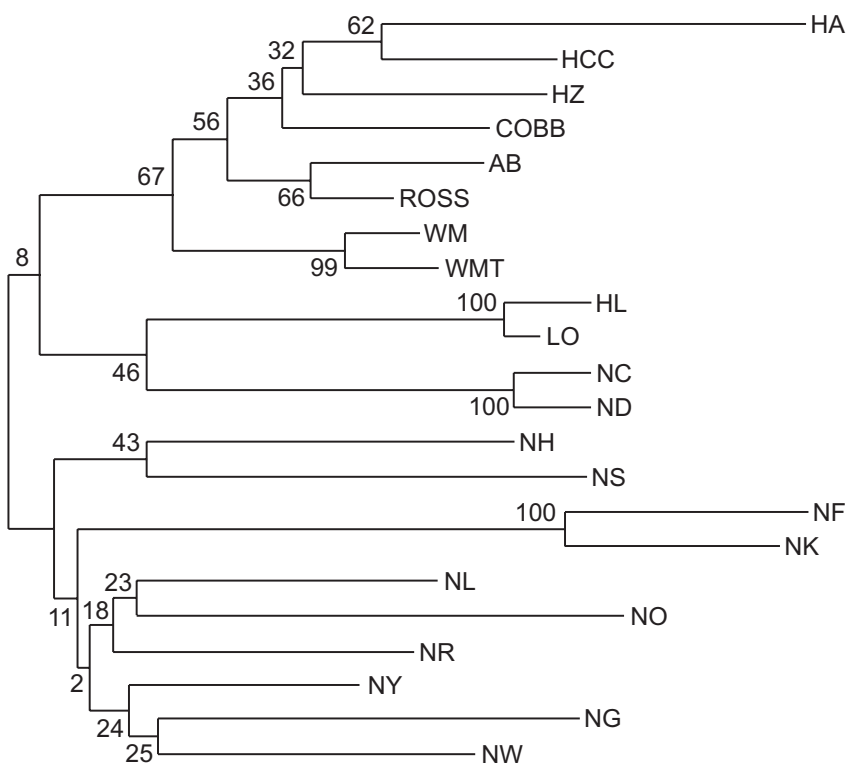

Fig. 3. Neighbor - Joining ( $\mathrm{NJ})$ tree show the genetic distances among the 22 breeds using Nei; $D_{A}$ genetic distance on the allele frequencies from 12 microsatellite microsatellite loci. The population acronyms are as follows; Arbor Acres (AB), Cobb (COBB), Hanhyup A L(HA), Hanhyup 3 (HCC), Hy-line Brown (HL), Hanhyup Z (HZ), Lohmann brown (LO), Rhode Island Red C (NC), Rhode Island Red D (ND), Leghorn F (NF), Gray Korea Native Chicken (NG), Black Cornish (NH), Leghorn K (NK), Black Korea Native Chicken (NL), Ogye (NO), Red Korea Native Chicken (NR), Brown Cornish (NS), White Korea Native Chicken (NW), Yellow Korea Native Chicken (NY), Ross (ROSS), Woorimatdag1 (WM), Woorimatdag2 (WMT).
NF) breeds that are clearly separated from other groups. Overall, it was confirmed that results similar to those of PCoA appeared.

The genetic divergences among the 22 chicken breeds based on allele frequencies were calculated according to DA genetic distance. The phylogenetic relationships among these 22 chicken breeds were determined using the neighbor-joining tree (Fig. 3). The genetic distances of 22 chicken breeds were in the range of 0.0515 (HL and LO) to 0.726 (HA and NK). The HL and LO were grouped into the same branch. Thus, the relationship between PCoA and FCA was very similar.

\section{DISCUSSION}

This study aimed to analysis the genetic diversity and population structure through 12 MS markers for Korea Chicken 22 breeds.

F-statistic were estimated in a fixation index as $\mathrm{F}_{s t}, \mathrm{~F}_{i t}$ and $\mathrm{F}_{\text {is }}$ among the $12 \mathrm{MS}$ markers. The estimated mean value of the $F_{s t}, F_{i t}$ and $F_{i s}$ were $0.183,0.231$ and 0.058 , respectively. The five out of 12 markers named ADL0293, LEI0094, MCW0029, MCW0123 and MCW0145 showed a negative number (Table 1). However, all the others 
showed a positive number. The $\mathrm{F}_{\text {is }}$ represents a degree of nonrandom mating (deviation from Hardy-Weinberg equilibrium) (Suh et al., 2014). And the expected probability of identity values of 12 MS markers were calculated in random individuals (PI), random half-sib $\left(\mathrm{PI}_{\text {half-sibs }}\right)$ and random sibs $\left(\mathrm{PI}_{\text {sibs }}\right)$, which were estimated as $3.65 \times 10^{-17}$, $1.13 \times 10^{-12}$ and $2.81 \times 10^{-6}$, respectively. Overall, the total expected probability (PE) of identity values was 98 . 11\% for the discrimination of Korean chicken breeds.

White leghorn (NF, NK) exhibited a lower degree of genetic diversity [NF: $\mathrm{MNA}=3.75, \mathrm{H}_{\mathrm{Exp}}=0.468, \mathrm{H} \mathrm{F}_{\mathrm{st}}=$ $0.392, \mathrm{PIC}=0.413 ; \mathrm{NK}: \mathrm{MNA}=3.92, \mathrm{H}_{\text {Exp }}=0.471, \mathrm{H}_{\text {Obs }}=$ 0.366 , PIC $=0.419)$ than all other breeds in all measures of genetic diversity whereas a high degree of diversity was observed in ROSS (MNA $=7.00, \mathrm{H}_{\text {Exp }}=0.710, \mathrm{H}_{\text {Obs }}=0.683$, PIC $=0.666)($ Table 2$)$. Heterozygosity was observed for White leghorn as quite low compared to other breeds which may be due to inbreeding among closely related breeds. In previous study, even though they have been obtained with different marker sets, white leghorn exhibited a lower degree of genetic diversity (MNA $=3.43, \mathrm{H}_{E x p}=0.416$, $\mathrm{H}_{\text {Obs }}=0.326$, PIC $=0.371$ ) (Suh et al., 2014). The current result was simiar to the one reported by Suh et al. (2014) and another study, the values for $\mathrm{H}_{E x p}$ and PIC reported by Kong et al. (2006) for Korean chicken breeds $\left(\mathrm{H}_{\text {Exp }}=0.630\right.$ and PIC $=0.552)$, Suh et al. (2014) for Korean chicken breeds $\left(\mathrm{H}_{\text {Exp }}=0.696\right.$ and PIC $\left.=0.653\right)$, Seo et al. (2017) for Korean chicken breeds $\left(\mathrm{H}_{\text {Exp }}=0.694\right.$ and PIC $\left.=0.650\right)$ and Choi et al. (2019) for Korean chicken breeds $\left(H_{E x p}=0.620\right.$ and PIC $=0.558$ ) were almost similar to the values obtained for the present analysis. These results indicated Korean chicken breeds have kept a high level of genetic diversity.

Fig. 1 illustrates the population relationships based on PCoA using individual multilocus genotypes of the $12 \mathrm{MS}$ markers. Clearly, based on the first component, Leghorn (NF, NK) was confirmed to be separated from the other groups. Cornish (NS, NH) was confirmed near the KNC, $\mathrm{HL}$ and LO by the second component. And it showed that HL and LO are genetically very close by the variance of first and second components. And the neighbor network analysis of the 22 breeds confirmed the FCA results as the Korean chicken breeds segregated in a similar pattern (Fig. $1,2)$. As a result of checking the genetic distance between groups by phylogenetic tree, it was confirmed to be the nearest genetic distance $(0.0515)$ for HL and LO and the farthest genetic distance (0.726) for HA and NK (Fig. 3).
This study is the analysis based on the 12 MS marker polymorphisms of the genetic diversity in the 22 Korean chicken breeds. Our results indicated that these multiplex PCR marker sets will have considerable applications in population genetic structure analysis. In addition, since the MS markers in this study are highly polymorphic, they can also be applied for the conservation, traceability and future improvement of these Korean chicken breeds.

\section{CONCLUSION}

In conclusion, we analyses the genetic diversity and population structure through 12 microsatellite (MS) markers for 22 Korean Chicken breeds. The reliability and power of identification using 12 MS markers were improved, and the genetic diversity and probability of individual discrimination were confirmed through statistical analysis. As a result of the genetic distance between groups by phylogenetic tree, it was confirmed to be the nearest genetic distance (0.0515) for Hy-line Brown (HL) and Lohman Brown (LO) and the farthest genetic distance (0.726) for HanHyup A (HA) and Leghorn K (NK).

\section{CONFLICTS OF INTEREST}

No potential conflict of interest relevant to this article was reported.

\section{ETHICS APPROVAL}

The study was approved by the Hankyong National University Animal Ethics Committee (No. 2018-2).

\section{ACKNOWLEDGEMENTS}

This study was supported by Golden Seed Project, funded by Korea Institute of Planning and Evaluation for Technology in Food, Agriculture and Forestry (IPET) [PJ01282005202101 (213010055WT251)].

\section{AUTHOR CONTRIBUTIONS}
Conceptualization: HSK
Data curation: YK, JHY, JS
Formal analysis: YK, JHY, SJM
Funding acquisition: HSK 
Investigation: YK, JHY

Methodology: YK, JHY, HSK

Project administration: HSK

Resources: HSK

Software: YK

Supervision: HSK

Validation: SJM, JS, HSK

Visualization: YK, JHY, JS

Writing - original draft: YK, JS

Writing - review \& editing: SJM, JS, HSK

\section{AUTHOR'S POSITION AND ORCID NO.}

\author{
Kim Y, Doctor's Course, \\ https://orcid.org/0000-0001-8459-0519 \\ Yun JH, Masters's Course, \\ https://orcid.org/ 0000-0002-4558-2337 \\ Moon SJ, Master's Degree \\ https://orcid.org/0000-0001-5716-3407 \\ Seong $\mathrm{J}$, PhD, \\ https://orcid.org/0000-0003-0956-995X \\ Kong HS, Professor, \\ https://orcid.org/0000-0003-1144-016X
}

\section{SUPPLEMENTARY MATERIALS}

Supplementary material can be found via https://doi.12750/ JARB.36.3.154.

\section{REFERENCES}

Belkhir K, Borsa P, Chikhi L, Raufaste N, Bonhomme F. 2003. GENETIX version 4.04. Laboratoire Génome, Populations, Interactions, CNRS UMR 5000, Université de Montpellier II, France.

Berthouly C, Bed'Hom B, Tixier-Boichard M, Chen CF, Lee YP, Laloë D, Legros H, Verrier E, Rognon X. 2008. Using molecular markers and multivariate methods to study the genetic diversity of local European and Asian chicken breeds. Anim. Genet. 39:121-129.

Botstein D, White RL, Skolnick M, Davis RW. 1980. Construction of a genetic linkage map in man using restriction fragment length polymorphisms. Am. J. Hum. Genet. 32:314-331.

Cheng HH and Crittenden LB. 1994. Microsatellite markers for genetic mapping in the chicken. Poult. Sci. 73:539-546.

Choi NR, Seo DW, Jemaa SB, Sultana H, Heo KN, Jo C, Lee JH. 2015. Discrimination of the commercial Korean native chicken population using microsatellite markers. J. Anim. Sci. Technol. 57:5.
Choi SS, Seo JH, Han JM, Seong J, Lee JH, Kong HS. 2019. The development of multiplex PCR microsatellite marker sets for Korean chicken breeds. Int. J. Poult. Sci. 18:492-498.

Crooijmans RP, Groen AF, Van Kampen AJ, Van der Beek S, Van der Poel JJ, Groenen MA. 1996. Microsatellite polymorphism in commercial broiler and layer lines estimated using pooled blood samples. Poult. Sci. 75:904-909.

Heo KN, Choo HJ, Seo BY, Park MN, Jung KC, Hwangbo J, Kim HK, Hong EC, Seo OS, Kang BS. 2011. Investigation of TYR and MC1R polymorphisms in Korean native chickens and the commercial chickens. CNU J. Agric. Sci. 38:465-471.

Hillel J, Groenen MA, Tixier-Boichard M, Korol AB, David L, Kirzhner VM, Burke T, Barre-Dirie A, Crooijmans RP, Elo K, Feldman MW, Freidlin PJ, Mäki-Tanila A, Oortwijn M, Thomson P, Vignal A, Wimmers K, Weigend S. 2003. Biodiversity of 52 chicken populations assessed by microsatellite typing of DNA pools. Genet Sel Evol. 35:533-557.

Jung JS, Seong J, Lee GH, Kim Y, An JH, Yun JH, Kong HS. 2021. Genetic diversity and relationship of Halla horse based on polymorphisms in microsatellites. J. Anim. Reprod. Biotechnol. 36:76-81.

Kong HS, Oh JD, Lee JH, Jo KJ, Sang BD, Choi CH, Kim SD, Lee SJ, Yeon SH, Jeon GJ, Lee HK. 2006. Genetic variation and relationships of Korean native chickens and foreign breeds using 15 microsatellite markers. Asian-Australas. J. Anim. Sci. 19:1546-1550.

Park MN, Hong EC, Kang BS, Kim HK, Kim JH, Na SH, Chae HS, Seo OS, Han JY, Jeong JH, Hwangbo J. 2010. Chemical composition and meat quality of crossbred Korean native chickens (KNC). Korean J. Poult. Sci. 37:415-421.

Park SDE. 2001. The Excel microsatellite toolkit (version 3.1). Animal Genomics Laboratory, University College Dublin, Ireland. http://animalgenomics.ucd.ie/sdepark/ms-toolkit/

Roh HJ, Kim KW, Lee J, Jeon D, Kim SC, Ko YG, Mun SS, Lee HJ, Lee JH, Oh DY, Byeon JH, Cho CY. 2019. Genetic diversity of Korean native chicken populations in DAD-IS database using 25 microsatellite markers. Korean J. Poult. Sci. 46:65-75.

Saitou N and Nei M. 1987. The neighbor-joining method: a new method for reconstructing phylogenetic trees. Mol. Biol. Evol. 4:406-425.

Seo D, Lee DH, Choi N, Sudrajad P, Lee SH, Lee JH. 2018. Estimation of linkage disequilibrium and analysis of genetic diversity in Korean chicken lines. PLoS One 13:e0192063.

Seo DW, Hoque MR, Choi NR, Sultana H, Park HB, Heo KN, Kang BS, Lim HT, Lee SH, Jo C, Lee JH. 2013. Discrimination of korean native chicken lines using fifteen selected microsatellite markers. Asian-Australas. J. Anim. Sci. 26:316-322.

Seo JH, Lee JH, Kong HS. 2017. Assessment of genetic diversity and phylogenetic relationships of Korean native chicken breeds using microsatellite markers. Asian-Australas. J. Anim. Sci. 30:1365-1371.

Seo JH, Oh JD, Lee JH, Seo D, Kong HS. 2015. Studies on genetic diversity and phylogenetic relationships of Korean native chicken using the microsatellite marker. Korean J. Poult. Sci. 42:15-26. 
Suh S, Sharma A, Lee S, Cho CY, Kim JH, Choi SB, Kim H, Seong HH, Yeon SH, Kim DH, Ko YG. 2014. Genetic diversity and relationships of Korean chicken breeds based on 30 microsatellite markers. Asian-Australas. J. Anim. Sci. 27:13991405.

Tantia MS, Vijh RK, Mishra B, Kumar STB, Arora R. 2006. Multilocus genotyping to study population structure in three buffalo populations of India. Asian-Australas. J. Anim. Sci. 19:1071-1078.

Weir BS and Cockerham CC. 1984. Estimating F-statistics for the analysis of population structure. Evolution 38:1358-1370.

Wright DJ. 1965. General multiplicity theory. Proc. Lond. Math. Soc. s3-15:269-288. 